\title{
O currículo prescrito para educação inclusiva: a proposta curricular e a inclusão dos alunos com deficiência visual
}

Ana Cristina Felipe Miotto*

\section{Resumo}

Este trabalho refere-se à pesquisa de mestrado que objetivava investigar como as necessidades educacionais especiais dos educandos com deficiência visual eram abordadas no currículo e trabalhadas em uma sala de aula comum da rede municipal de ensino de Belo Horizonte, cuja proposta pedagógica fosse anunciada como inclusiva. Para o presente artigo, será apresentada a análise do currículo prescrito da escola investigada, identificando como esta aborda o tema inclusão em seus documentos oficiais e apontando como estes documentos definem os princípios da educação inclusiva e as necessidades educacionais especiais dos educandos nela matriculados. Sabendo da importância do currículo no processo educacional e que a reformulação deste é a chave para a inclusão, a pesquisa se desenvolveu em torno das implicações do currículo no processo educacional dos alunos com deficiência visual. Para a realização deste estudo, buscou-se uma aproximação entre as teorias do currículo e os princípios da inclusão, a fim de verificar a convergência de seus discursos e as representações que se enredam no discurso curricular da instituição investigada, a partir das proposições que tomaram visibilidade nos discursos da educação inclusiva, enunciados nos documentos institucionais da escola.

Palavras-chave: Currículo. Deficiência visual. Inclusão.

\section{Prescribed curriculum for inclusive education: curriculum proposal and inclusion of students with visual impairments}

\section{Abstract}

This paper refers to a master thesis that aimed to investigate how the special educational needs of students with visual impairments were addressed in the curriculum and worked in a regular classroom at a municipal school of Belo Horizonte, whose pedagogical proposal was advertised as inclusive. To this article will be presented the analysis of the prescribed curriculum of the investigated school, identifying how this school addresses the issue inclusion in its official documents, and explaining how these documents define the principles of inclusive education and special educational needs of students enrolled in that school.

\footnotetext{
* Professora mestre em Educação pela Pontifícia Universidade Católica de Minas Gerais, Belo Horizonte, Minas Gerais, Brasil.
} 
Knowing the importance of curriculum in the educational process, and that its reformulation is the key to inclusion, the research has developed around the implications of the curriculum in the educational process of students with visual impairments. For this study, we sought an approach between theories of curriculum and the principles of inclusion, in order to check the convergence of their discourses and the representations that are entangled in the curriculum discourse of the investigated school, from the propositions that took visibility in the speeches of inclusive education, listed in the institutional documents of that school.

Keywords: Curriculum. Visual impairment. Inclusion.

\section{Introdução}

A atual organização da educação nacional contempla, entre outras dimensões do direito à educação, o princípio da inclusão. Apesar da seguridade legal, estamos vivenciando um processo de transição de paradigmas, transição do paradigma da integração, com resquícios do paradigma da segregação, para o princípio da inclusão. Dessa forma, de acordo com o princípio da inclusão, que cada vez mais se estabelece na sociedade, é fundamental que os alunos não sejam apenas aceitos nas escolas, mas que estas Ihes assegurem sua permanência e sua efetiva participação nas aulas e demais atividades escolares, objetivando o seu desenvolvimento.

De acordo com Carvalho (2004), a educação inclusiva visa à universalização da educação de qualidade para todos, ou seja, pressupõe novas respostas educativas para a efetivação do trabalho na diversidade, através de um currículo que englobe arranjos organizacionais, estratégias de ensino e o uso de recursos apropriados aos alunos com habilidades e interesses diferentes. $O$ currículo nestas escolas deve ser significativo, deve ser um instrumento de efetivação do direito de todos à educação, e abrangente, pois as práticas educacionais devem não só respeitar a aprendizagem do aluno, mas também corresponder às necessidades especiais de aprendizagem apontadas por todos.

Em uma escola inclusiva, a ênfase deve estar na organização de um currículo que ofereça respostas às necessidades educativas especiais de cada aluno dentro da sala de aula comum, em contraponto ao currículo tradicional, fortemente compartimentado em disciplinas e mais centrado nos conteúdos do que nos processos. As escolas inclusivas devem revelar a incorporação do princípio da diversidade e o abandono da tradicional ideia do alunado homogêneo em seu currículo. O projeto político pedagógico nas escolas inclusivas deve ser um processo em constante revisão e aprimoramento por sustentar sua proposta de educação e seu trabalho pedagógico.

Quando o assunto é a inclusão de alunos com deficiência, há a necessidade de se estabelecer, no contexto do currículo regular, o apoio instrucional a ser disponibilizado a estes, através de redes de apoio proporcionadas por serviços especializados e pela escola, para a orientação dos professores das clas- 
ses comuns, a introdução nas escolas dos recursos materiais e das técnicas pedagógicas específicas para que se estimule a independência e a autonomia desses alunos.

O presente estudo buscou investigar os avanços e impasses para a consolidação da inclusão dos educandos com deficiência visual, através da realização de um estudo de caso em uma escola da rede municipal de Belo Horizonte. Procurou-se investigar como as necessidades educacionais especiais desses educandos foram abordadas no currículo de uma escola regular da rede pública de ensino, cuja proposta pedagógica fosse anunciada como inclusiva e que tivesse alunos com deficiência visual matriculados. Para alcançar a finalidade da pesquisa, foram estabelecidos os seguintes objetivos: identificar em quais documentos institucionais a escola abordava o tema inclusão, explicitar como estes documentos definiam os princípios da educação inclusiva, e descrever de que maneira e em que momentos as necessidades educacionais especiais dos alunos com deficiência visual foram abordadas, ou não, no currículo formal da escola.

\section{O currículo enquanto campo de estudo}

O currículo é um campo de estudo e prática de importância central na área da educação. Estudar e compreender um campo tão complexo como o do currículo requer que se investigue o seu reflexo nas questões do espaço escolar, o entendimento de que as atividades curriculares, tanto teóricas quanto práticas, não são isoladas das lutas econômicas, políticas e ideológicas na sociedade como um todo.

Nas discussões sobre o campo do currículo atualmente, estão presentes debates que giram em torno das diferenças, do multiculturalismo, das relações de gênero, raça e sexo, das políticas de inclusão, ou seja, a democratização do ensino para todos. Seja mediante o acesso ao sistema de ensino, seja sobre as políticas públicas para viabilizar a permanência na escola, o cerne destes debates é a trajetória escolar, a justiça e a igualdade social (CONNELL, 1995; COSTA, 1998; GARCIA; MOREIRA, 2003; LOPES; MACEDO, 2002).

As teorias críticas de currículo demonstraram como o currículo tradicionalmente estava comprometido com a seleção cultural dos padrões hegemônicos na sociedade e apontaram também as tendências de ressignificação desse processo que, assim, pôde reverter sua história de exclusão. Hoje, procura-se defender um currículo inclusivo ou um currículo direcionado para a conquista da equidade na escola. Este pensamento curricular procura compreender esta nova orientação, pós-crítica, mantendo a perspectiva crítica no debate sobre o sistema educacional, entendido como um elemento na manutenção das relações dominantes na sociedade e procurando também compreender e superar os entraves das práticas pedagógicas produtoras de exclusão. 
É fundamental, no campo do currículo, que se abordem as diferenças, mas não é possível falar em currículo sem se falar em poder, inclusão, exclusão, pois é neste espaço que se afirmam e se fortalecem as diferenças utilizadas como argumentos lógicos e naturais, que têm funcionado como justificativa para a desigualdade e a exclusão. Neste panorama, a escola torna-se um lugar privilegiado de troca de ideias, de encontros, de legitimação de práticas sociais e de interação. Isto se deve à sua ação sistemática na transmissão de conhecimentos, nas regras estabelecidas, nos comportamentos determinados, nas normas organizadas, nos valores aferidos e nos elementos de diferentes culturas postos em contato (GOODSON, 2005).

De acordo com Forquin (1993), o currículo revela as relações de poder e escolha. Ao selecionar o que deve ser ensinado e transmitido, exercita-se o poder, pois conteúdos, valores e crenças são escolhidos em detrimento de outros. Ao fazer a escolha, inclusões e exclusões são feitas, objetivando, muitas vezes, um controle social. Esta forma de controle é transmitida tanto pelas disciplinas e conteúdos, como por comportamentos e ações rotineiras, valores, e regras sociais. É neste sentido que a ação pedagógica escolar tem um papel preponderante, pois é na escola que o indivíduo aprende e consolida, muitas vezes, seus valores.

Na teoria crítica do currículo, alguns temas foram preponderantes para o estabelecimento da discussão atual sobre o currículo: reprodução cultural e social, poder, currículo oculto e resistências, mas a teoria crítica levantou também novas questões a serem refletidas, como: o multiculturalismo, as questões de gênero, raça, etnia, sexualidade, e também as necessidades especiais, que hoje tomam conta dos debates em diferentes espaços sociais, dentre eles, a escola e o currículo (APPLE, 1994). Junto ao debate crítico do currículo, encontra-se, assim, o debate pós-crítico do currículo, e o ponto de partida é que nas salas de aula nem todas as vozes são igualmente valorizadas, por isso a necessidade do diálogo entre as diferenças precisa ser incentivado.

O momento atual do campo do currículo é um momento em que se busca identificar as vozes autorizadas e as vozes silenciadas. O que se discute é a ideia de que o currículo precisa dar voz às minorias que foram excluídas das escolas. Cobram-se da educação e do currículo medidas para a formação de cidadãos conscientes e democráticos, pois "o que caracteriza propriamente os seres humanos não é uma similaridade, mas a própria diferença" (MOREIRA, 2002, p. 22).

\section{Currículo e inclusão}

É no campo do currículo que o debate sobre inclusão tem sido favorecido. Quando se fala em inclusão, fala-se em inovação, na transformação da sociedade pautada em verdades que se colocavam como universais, da legitimação de valores e culturas para uma sociedade que se percebe heterogênea e que permite que apareçam as diferenças. A inclusão reconhece a 
especificidade do sujeito ao perceber que não se encontra apenas nele os rumos do seu processo de desenvolvimento, mas no contexto social em que está inserido.

É certo que as relações de poder ainda presidem a produção das diferenças nas escolas, baseadas numa concepção de igualdade que, na verdade, promove a homogeneidade, ainda provinda de um modelo tradicional de ensino, em que a desigualdade justifica a fragmentação do ensino em seriações, classificações, hierarquias de capacidade e conhecimento.

De acordo com Sacristán (2002), a diversidade ou diferenças não são apenas manifestações do ser único que cada um é. Em muitos casos, apresenta-se sob manifestações, possibilidades de ser ou de chegar a ser e de ter possibilidades de participar dos bens sociais, culturais e econômicos.

A sociedade está vivenciando um momento de transição, a meta é a instauração de uma sociedade inclusiva, que objetiva oferecer oportunidades iguais, para que cada pessoa se torne autônoma e autodeterminada. A sociedade inclusiva se constitui como democrática e repousa em princípios como a aceitação das diferenças individuais, a valorização de cada pessoa, a convivência dentro da diversidade humana e a aprendizagem através da cooperação, reconhecendo o direito de todos (MOREIRA, 2006).

A inclusão se concretizará, portanto, quando existir uma mudança na forma de tratar e de educar as pessoas, respeitando-Ihes as diferenças e as singularidades. A inclusão pressupõe um movimento dinâmico e permanente que reconhece a diversidade humana e tem como fundamento a igualdade na participação e na construção do espaço social. A inclusão é, portanto, um processo que busca remover as barreiras impostas pela exclusão e o desafio está em lançar propostas que não se destinem apenas a um grupo de pessoas, mas a todas as possibilidades da existência humana.

A inclusão hoje, assumida como um novo paradigma mundial, defende uma sociedade mais justa e mais democrática, livre das práticas discriminatórias e segregacionistas que marcaram a história da humanidade. O movimento da inclusão é decorrente de uma concepção de mundo democrática, fundada no respeito aos direitos humanos, segundo os quais as pessoas devem ser respeitadas, independentemente do sexo, origens étnicas, opção sexual ou deficiências (SACRISTÁN, 2002).

De acordo com Pacheco, Eggertsdóttir e Mrinósson (2007), a educação inclusiva tem sido discutida em termos de justiça social, pedagogia, reforma escolar e melhoria nos programas educacionais. As práticas pedagógicas em uma escola inclusiva precisam refletir uma abordagem mais diversificada, flexível e colaborativa do que na escola tradicional. A inclusão pressupõe que a escola se ajuste a todas as crianças que desejam se matricular em sua localidade, em vez de esperar que uma criança com determinada necessidade especial se ajuste à escola. 
A Declaração de Salamanca é um marco na educação inclusiva e nela foi proclamado que toda criança tem direito fundamental à educação e deve ser dada a oportunidade de atingir e manter o nível adequado de aprendizagem independente de suas características, interesses, habilidades e necessidades de aprendizagem. De acordo com a Declaração, as escolas regulares que possuam orientação inclusiva constituem os meios mais eficazes de combater atitudes discriminatórias, criando-se comunidades acolhedoras. O princípio fundamental da escola inclusiva é que todas as crianças devem aprender juntas, independentemente das diferenças. As escolas inclusivas devem reconhecer e responder às necessidades diversas de seus alunos, através de um currículo que leve em conta o ritmo, as estratégias de ensino e o uso de recursos apropriados a cada aluno.

Pode-se observar a importância do currículo e a sua reformulação como sendo o alicerce da inclusão educacional. A elaboração de um Projeto Político Pedagógico para as escolas evidencia os valores que esta cultua e o percurso para se atingir a intencionalidade educativa. As discussões e a elaboração do Projeto Político Pedagógico devem incorporar a comunidade escolar como um todo, e o texto deve estar sempre em processo de aprimoramento.

Segundo Sacristán (2000), o currículo precisa considerar as oportunidades desiguais frente ao mesmo, assim, as ações centradas no currículo devem assentar-se sobre o prisma de que a escola, por si só, não pode superar as desigualdades, mas abarcar as diferenças é fundamental para um modelo ideal de currículo. Sendo a escola parte constitutiva do social, ela reflete os desdobramentos de todas as transformações ocorridas na sociedade. A escola é o lócus preferencial, pois é uma instituição formadora de cidadãos; assim, o paradigma da inclusão social abarcou a educação, preconizando a educação inclusiva, acreditando ser a partir dela que todas as outras instituições e setores sociais se tornarão inclusivos.

Ainda de acordo com Sacristán (2002), é através do processo educacional que se capacita o aluno para o exercício da liberdade e da autonomia, isto implica respeito para com o sujeito, que é único, e respeito para com suas manifestações, ou seja, uma educação aberta a todos e com iguais oportunidades. Isto tem implicações para a concepção de uma proposta curricular inclusiva e para sua efetivação. Os currículos que reconhecem e que valorizam as diferenças têm projetos inclusivos de educação, almejam um ensino de qualidade a partir de ações educativas pautadas na solidariedade, na colaboração, no compartilhamento do processo educativo com todos os que estão direta ou indiretamente envolvidos.

\section{A proposta curricular para as escolas inclusivas}

Nas escolas inclusivas, o currículo é caracterizado por sua habilidade de incorporar conteúdos que promovam, além do desempenho acadêmico, as habilidades sociais. Este currículo representa uma estrutura para professores, 
os serviços de apoio e as famílias, que devem, de forma conjunta, planejar o processo educacional. Para atender à diversidade, o currículo e as atividades em sala de aula devem ser dirigidos a todos os alunos, modificando atitudes discriminatórias e promovendo uma educação de qualidade em uma sociedade inclusiva. Um currículo que se baseia na diversidade, desconstrói todo o modelo de hierarquização e de relações de poder que inferiorizam o diferente, dando lugar à pluralidade, ao reconhecimento das diferenças, à consciência do individual e ao mesmo tempo do todo, ou seja, o direito à igualdade de oportunidades e não de um modo igual de educar a todos.

O currículo prescrito pode ser entendido como a base da organização escolar. Neste documento, organizado e elaborado preferencialmente pela equipe pedagógica da escola, deve conter: aspectos filosóficos e os objetivos da instituição; a organização interna da escola; as práticas pedagógicas em sala de aula (programas, conteúdos, atividades e avaliações) e quaisquer outras orientações que forem relevantes para a instituição, alunos e familiares dos alunos.

\begin{abstract}
O currículo comum não deve ser entendido apenas como a soma de conteúdos que todos estão de acordo que sejam objetos de ensino; menos ainda deve-se cair num totalitarismo que apague toda a diferença individual ou de grupo. A cultura comum deve admitir a tolerância frente à dissensão e incorporar uma dimensão multicultural para entender a diversidade de valores, crenças, modos de entendimento e de vida (SACRISTÁN, 1998, p. 173).
\end{abstract}

A presente pesquisa se propôs a analisar o currículo prescrito de uma escola regular da rede municipal de Belo Horizonte, seu discurso pedagógico e sua organização do trabalho escolar, destacando como esta instituição pretende trabalhar com as diferenças existentes no espaço da ambiência escolar, ou seja, como o currículo prescrito aborda o tema inclusão e as necessidades educacionais especiais dos alunos com deficiência visual.

O objetivo desta análise foi verificar os termos em que a proposta curricular da escola investigada pode ser considerada inclusiva, tendo como fundamento o compromisso estabelecido pela escola de desenvolver uma prática escolar democrática e de disponibilizar uma educação de qualidade a todos os alunos. Ao se analisar o PPP da escola, buscou-se identificar o caráter emancipatório das mudanças que ela pretende introduzir no cotidiano escolar.

No âmbito dos documentos prescritos pela instituição investigada, o documento que retratava a proposta pedagógica da instituição e que foi norteador para análise foi o Projeto Político Pedagógico (PPP). A consulta ao PPP foi realizada na própria escola, e é importante destacar que este documento datava de 2006 e a pesquisa foi realizada durante o ano de 2009. Segundo a coorde- 
nação da escola, o PPP ainda estava em construção e durante a consulta pôdese verificar algumas correções sendo feitas em seu texto.

A escola ao elaborar seu PPP, considerado por esta o documento orientador das atividades curriculares e da organização escolar, traduzidas nos compromissos da instituição, optou pela metodologia de planejamento coletivo. Tendo como princípio a prática democrática, professores, integrantes da equipe pedagógica e administrativa, funcionários, alunos e pais foram chamados a assumir a função de sujeitos que discutem a prática escolar que desejam.

O projeto pedagógico da instituição sustenta que o conhecimento do mundo não acontece apenas mediante as relações escolares, porém, a escola ainda é considerada como um lugar privilegiado para a construção dos saberes. A organização escolar e a organização curricular objetivam respeitar as características individuais e os interesses dos educandos, visando à compreensão crítica e à formação ética em seu processo de construção do conhecimento. Buscando respeitar o ritmo e a singularidade de cada aluno, a organização do ensino, na escola, acontece em ciclos de formação.

O Ensino Fundamental, segmento analisado nesta pesquisa, é organizado em ciclos trianuais, totalizando nove anos de duração: $1^{\circ}$ ciclo, de 06 a 08 anos; $2^{\circ}$ ciclo, de 09 a 11 anos; $3^{\circ}$ ciclo, de 12 a 14 anos. Sobre a organização escolar em ciclos, o Plano Curricular Nacional ressalta a importância da adoção de ciclos pela flexibilidade que possibilita trabalhar melhor com as diferenças, já que cada aluno tem desempenho muito diferente na relação com objetos de conhecimento diferentes; e a prática escolar tem buscado incorporar essa diversidade de modo a garantir respeito aos alunos e a criar condições para que possam progredir nas suas aprendizagens.

De acordo com o projeto pedagógico, os educadores da escola investigada entendem a educação como um processo de construção e desenvolvimento do aluno em contato com o ambiente, com os outros e com a sociedade. Sendo assim, a organização curricular da escola é estabelecida abrangendo as áreas de conhecimento que compõem as indicações dos Parâmetros Curriculares Nacionais (PCN) e as Proposições Curriculares para o Ensino Fundamental da Rede Municipal de Educação de Belo Horizonte - Artes, Ciências Naturais, Educação Física, Geografia, História, Língua Portuguesa, Língua Estrangeira e Matemática - desdobradas em disciplinas que se desenvolvem de forma articulada às áreas do conhecimento.

Ainda segundo o documento, a instituição pretende proporcionar uma proposta aberta e flexível, que ofereça instrumentos norteadores para a educação sem constituir um modelo curricular homogêneo e impositivo. Neste sentido, a educação ultrapassa o espaço da escola e se incide no cotidiano do educando; por isto, a importância de se utilizar variados recursos pedagógicos, buscando favorecer a reflexão, estimular o trabalho em grupos cooperativos, a pesquisa e a criatividade. 
Em relação aos seus fundamentos epistemológicos, políticos e sociais, o foco da proposta da escola é uma aprendizagem contextualizada, que não pode ser separada da compreensão crítica e da formação ética. A escola defende a cooperação, o diálogo, a aceitação e a compreensão da diversidade com o objetivo de desenvolver uma postura ética e política em seus alunos, acolhendo e valorizando as diferenças, estimulando discussões e possibilitando a democracia, a solidariedade e o desenvolvimento de cidadãos críticos.

Estes indicadores permitem concluir que a escola, na proposta curricular prescrita, declara estar comprometida com a efetivação da democratização escolar, garantindo a todos o acesso à escola, ao conhecimento e à promoção de experiências socioculturais significativas para a construção de condutas adequadas à sociedade democrática.

\title{
O currículo prescrito e a inclusão dos alunos com necessidades educacionais especiais
}

Uma ação educativa comprometida com a cidadania e com a formação de uma sociedade democrática, proposta a promover o convívio com a diversidade, formará cidadãos conscientes e capazes de lidar com as diferenças. Este é o papel da escola inclusiva: educar a todos sem discriminação, e dentro deste todos estão os alunos com necessidades educacionais especiais.

Nos documentos acessíveis, a escola investigada revelou uma proposta inclusiva, com o objetivo de formar pessoas que respeitem as diferenças. Isso permite afirmar que o currículo apontava a escola como aberta a todos, independente de qualquer especificidade, visando formar pessoas solidárias, críticas e participativas.

\begin{abstract}
Hoje a escola se reconhece na diversidade e na luta contra os processos sociais excludentes. E acreditando sempre no poder da educação, realiza projetos e atividades que [...] visam respeitar a diversidade sócio cultural, étnico racial e de gênero, afetiva, de ritmo de aprendizagem, dentre outras. (Projeto Político Pedagógico da escola investigada)
\end{abstract}

Projeto Político Pedagógico da escola é apresentado como um documento democrático e sujeito à permanente reflexão coletiva, uma vez que preconiza o diálogo entre os diversos sujeitos que constituem o universo escolar. Nesta perspectiva, ele não é imposto como algo pronto e acabado, mas como uma proposta aberta a reelaborações e reestruturações de acordo com as necessidades percebidas em seu cotidiano.

Um dos principais requisitos de uma proposta curricular aberta à inclusão é esta possibilidade de se realizar adaptações, levando-se em consideração tanto as diferenças individuais dos alunos, quanto as experiências já realizadas e as dificuldades e saídas encontradas. 
Embora a escola abordasse a temática da inclusão em seu documento institucional, esta não define de forma clara os princípios da educação inclusiva. Pôde-se constatar também que eram restritos os escritos que tratassem especificamente das necessidades educacionais especiais. Esta temática não foi abordada de forma explícita no currículo formal da instituição, apesar de ter alunos das mais diversas especificidades matriculados, além dos alunos com deficiência visual.

A LDBN, em seu artigo 59, estabelece que os sistemas de ensino assegurarão aos educandos com necessidades especiais currículos, métodos, técnicas, recursos educativos e organização específicos para atender às suas necessidades. O Decreto n. 6. 571/08 define o atendimento educacional especializado como conjunto de atividades, recursos de acessibilidade e pedagógicos organizados institucionalmente, prestado de forma complementar ou suplementar à formação dos alunos no ensino regular, e este atendimento deve integrar a proposta pedagógica da escola, envolver a participação da família e ser realizado em articulação com as demais políticas públicas.

Contudo, a escola investigada, apesar de matricular alunos com deficiência visual, cegos ou com baixa visão, nada consta em seu PPP em relação à atuação da escola para com estes alunos, sobre os recursos didáticos a serem disponibilizados, que são de fundamental importância para o seu processo de ensino e aprendizagem, e muito menos as complementações curriculares específicas para a educação de alunos com baixa visão e alunos cegos - atividades de vida diária, orientação e mobilidade, o Soroban e o Sistema Braille -, que serviriam de orientação para os membros da escola, assim como para a escola orientar as famílias dos alunos com deficiência visual.

Nos documentos da escola, fica claro o discurso da proposta formal de inclusão. Mas os ideais da educação inclusiva, para além do acesso à escola, não receberam, nos documentos, indicadores que garantam a efetiva educação dos alunos com necessidades educacionais especiais. Este é um fator preocupante, pois contribui para a presença de lacunas ao desenvolvimento de uma proposta de atendimento às diferenças nessa instituição.

Após análise do documento, fica evidente que a apresentação da proposta curricular em relação ao processo de inclusão dos alunos com necessidades educacionais especiais é genérica e deixa a desejar como documento de orientação pedagógica, não oferecendo embasamento para o norteamento das atividades curriculares em sala de aula. 


\section{Para finalizar}

Desfazer a lógica da exclusão escolar passa pela desconstrução dos currículos e dos processos escolares centrados na discriminação, para avançar na direção de uma educação que contemple as potencialidades, probabilidades, facilidades e equiparação de oportunidades, para todos os alunos, independente de suas diferenças. Apesar do reconhecimento da inclusão como processo de fato nas escolas, investigações realizadas para verificar como se efetivam os currículos chamados inclusivos têm evidenciado as dificuldades e os limites decorrentes de práticas pedagógicas cristalizadas na escola não inclusiva. (MALLETTA, 2008; XAVIER, 2008).

Não basta reiterar que a educação para todos é garantia de democratização. É fundamental uma mudança de postura de todos os membros da escola. É necessária a reestruturação do ensino que contemple a reformulação dos objetivos do ensino e a celebração da diversidade. A inclusão se concretizará quando existir uma mudança na forma de tratar e de educar as pessoas, respeitando-lhes as diferenças e as singularidades. Se o que se almeja nas escolas é uma educação que visa à formação de cidadãos conscientes e democráticos, é importante que se trate e se debata as diferenças no âmbito escolar, começando pelo currículo.

\section{Referências}

APPLE, M. W. Repensando ideologia e currículo. In: MOREIRA, A. F.; SILVA, T. T. (Org.). Currículo, cultura e sociedade. São Paulo: Cortez, 1994, p. 39-57.

CARVALHO, R. E. Educação inclusiva: com os pingos nos "is". Porto Alegre: Mediação, 2004.

CONNELL, R. W. Pobreza e educação. In: GENTILI, P. (Org.). Pedagogia da exclusão: crítica ao neoliberalismo em educação. Petrópolis: Vozes, 1995, p. 11-42.

COSTA, M. V. O currículo nos limiares do contemporâneo. Rio de Janeiro: DP\&A, 1998.

FORQUIN, J. C. Escola e cultura: as bases epistemológicas do conhecimento escolar. Porto Alegre: Artes Médicas,1993.

GARCIA, R. L.; MOREIRA, A. Flavio (Org.). Currículo na contemporalidade: incertezas e desafios. São Paulo: Cortez, 2003.

GOODSON, I. Currículo: teoria e história. Petrópolis: Vozes, 2005.

LOPES, A. C.; MACEDO, E. (Org.). Currículo, debates contemporâneos.

São Paulo: Cortez, 2002. 
MALLETTA, A. P. B. O currículo e a sala de aula: um olhar sobre as diferenças nas séries iniciais do ensino fundamental. 2008. 182 f. Dissertação (Mestrado em Educação)-Pontifícia Universidade Católica de Minas Gerais, Belo Horizonte, 2008.

MOREIRA, A. F. B. Currículo, diferença cultural e diálogo. Educação e Sociedade, ano XXIII, n. 79, p. 15-38, ago. 2002.

MOREIRA, A. F. B. (Org.). Currículo: questões atuais. Campinas, São Paulo: Papirus, 2006.

PACHECO, J.; EGGERTSDÓTTIR, R.; MARINÓSSON, G. L. Caminhos para a inclusão: um guia para o aprimoramento da equipe escolar. Porto Alegre: Artmed, 2007.

SACRISTÁN, J. G. Compreender e transformar o ensino. Porto Alegre: Artmed,1998.

SACRISTÁN, J. G. Currículo: uma reflexão sobre a prática. Porto Alegre: Artmed, 2000.

SACRISTÁN, J. G. A Construção do discurso sobre a diversidade e suas práticas. In: Atenção à diversidade. Porto Alegre: Artmed, 2002, p. 13-33.

XAVIER, G. do C. O currículo e a educação inclusiva: a prática curricular e suas implicações na inclusão escolar de alunos com necessidades educacionais especiais. 2008. 196f. Dissertação (Mestrado em Educação)-Pontifícia Universidade Católica de Minas Gerais, Belo Horizonte, 2008.

\section{Correspondência}

Ana Cristina Felipe Miotto - Rua Moreira César, 78, apartamento 401, bairro Gutierrez, Belo Horizonte, MG. CEP: 30441-155.

E-mail: anamiotto@yahoo.com.br

Recebido em 07 de abril de 2010

Aprovado em 30 de maio de 2010 